\title{
HUBUNGAN DURASI PENGGUNAAN MEDIA SOSIAL DENGAN MOTIVASI BELAJAR REMAJA
}

\author{
Hana Nur Rahmawati ${ }^{1}$, Muhammad Khabib Burhanuddin Iqom ${ }^{1}$, Hermanto ${ }^{1}$ \\ ${ }^{1}$ Program Studi Ilmu Keperawatan, STIKES Kendal \\ ${ }^{2}$ Program Studi Ilmu Keperawatan, Sekolah Tinggi Ilmu Kesehatan Kendal \\ hanaswag149@gmail.com
}

\begin{abstract}
ABSTRAK
Internet merupakan rangkaian komputer yang terhubung dalam beberapa rangkaian jaringan. Salah satudi antaranya yaitu media sosial yang merupakan situs dimana seseorang bias membuat Web page pribadi kemudian terhubung dengan teman-teman untuk berbagi informasi dan berkomunikasi. Penggunaan media social sangat mempengaruhi aktivitas seseorang, salah satunya adalah motivasi belajar remaja. Tujuan penelitian ini adalah untuk mengetahui hubungan durasi penggunaan media social dengan motivasi belajar remaja di SMAN 1 Gringsing. Desain yang digunakan adalah deskriptif korelasi dengan pendekatan cross sectional. Sampel pada penelitian sebanyak 239 responden. Pengambilan sampel menggunakan Simple Random Sampling. Hasil penelitian menunjukkan bahwa ada hubungan antara durasi penggunaan media sosial dengan motivasi belajar remaja di SMAN 1 Gringsing responden yang menggunakan durasi media sosial dengan jumlah paling banyak masuk dalam kategori durasi rendah yaitu 152 responden $(63,6 \%)$ dan responden motivasi belajar rata-rata masuk dalam kategori motivasi belajar sedang dengan jumlah 176 responden $(73,6 \%)$ dengan $\rho$-value $=0,000<\alpha(0,05)$. Remaja sebaiknya mampu menyesuaikan waktu penggunaan media sosial dengan baik sehingga tidak lalai terhadap tugasnya sebagai pelajar.
\end{abstract}

Kata Kunci: Media sosial, motivasi belajar.

\section{RELATIONSHIP OF DURATION OF USE OF SOCIAL MEDIA WITH TEEN LEARNING MOTIVATION}

\begin{abstract}
The internet is a series of computers that are connected in a series of networks. One of them is social media, which is a site where someone can create a personal Web page and then connect with friends to share information and communicate. The use of social media greatly influences a person's activities, one of which is the motivation to learn teenagers. The purpose of this study was to determine the relationship between the duration of the use of social media and the motivation to learn adolescents at Gringsing 1 Public High School. The design used is descriptive correlation with cross sectional approach. The sample in the study were 239 respondents. Sampling uses Simple Random Sampling. The results showed that there was a relationship between the duration of the use of social media and the motivation to learn adolescents at SMAN 1 Gringsing respondents who used the duration of social media with the highest number included in the low duration category of 152 respondents (63.6\%) and respondents average learning motivation included in the category of moderate learning motivation with a total of 176 respondents (73.6\%) with $\rho$ value $=0,000<\alpha(0.05)$. Teenagers should be able to adjust the time of using social media so that they are not negligent about their duties as students.
\end{abstract}

Keywords: Social media, learning motivation.

\section{PENDAHULUAN}

Semakin berkembangnya ilmu pengetahuan dan teknologi dan informasi yang semakin meningkat pesat sekarang ini, masyarakat tidak dapat dipisahkan dari penggunaan internet. Internet merupakan suatu hasil dari kemajuan ilmu pengetahuan dan teknologi buatan manusia. Internet singkatan dari interconected networking yang apabila diartikan berarti rangkaian komputer yang terhubung dalam beberapa rangkaian jaringan. Dengan adanya internet setiap orang dapat mengakses informasi dengan lebih cepat, efisien serta dapat melakukan berbagai hal dengan siapapun dan dimanapun tanpa batas waktu dan tempat. Seiring berjalannya dengan internet, perkembangan media sosialpun merambat luas dimasyarakat mulai dari anak usia sekolah dasar hingga dewasa. (Hutahahean, 2012).

Pada tahun 2014, data menunjukkan pengguna internet dunia diperkirakan sudah melampaui 2,2 
milyar atau sekitar 30\% dari total populasi dunia. Negara yang menggunakan media sosial terbesar diantaranya adalah Filipina yang penggunaan internetnya mencapai $29,7 \%$, Facebook mencapai $93,9 \%$, sedangkan di negara Malaysia penggunaan internet mencapai $64,6 \%$ dan penggunaan media social Facebook 64,6\%.Di Indonesia padatahun 2014 Pengguna internet mencapai $15 \%$ atau 38,2 juta dari total jumlah penduduk sekitar 251,2 juta jiwa, sedangkan pengguna jejaring social juha sekitar 15\% dari total jumlah penduduk indonesia. Dan diprediksi penggunanya dalam beberapa tahun kedepan akan meningkat tajam" (Kementrian Perdagangan RI, 2014).

Menurut, Kementrian Komunikasi dan Informatika (Kemenkominfo), sebanyak 63 juta orang di Indonesia adalah pengguna internet dan 95\% diantaranya adalah pengguna situs jejaring sosial. Hasil survei asosiasi penyelenggara jasa internet. Internet merupakan suatu hasil dari kemajuan ilmu pengetahuan dan teknologi buatan manusia. Internet singkatan dari interconected networking yang apabila diartikan berarti rangkaian internet Indonesia menunjukkan pertumbuhan penggunaan internet di Indonesia terus meningkat menjadi $79.72 \%$. Di tahun 2012, penetrasi penggunaan internet di wilayah Indonesia mencapai 24.23\% (APJII,2012). Jumlah ini merupakan potensi luar biasa, apalagi jika dibandingkan dengan jumlah penduduk Indonesia yang mencapai 260 juta jiwa dan juga merupakan jumlah yang sangat besar bila dibandingkan dengan penetrasi internet di negara-negara sekitar indonesia, baik di Asia Tenggara maupun Australia.

Seiring berjalannya waktu, telah terjadi pergeseran budaya, dari budaya media tradisional yang berubah menjadi budaya media yang digital. Keberadaan media sosial telah mengubah bagaimana akses terhadap teknologi digital berjaringan. Untuk menghadapi perkembangan ilmu pengetahuan dan teknologi yang semakin canggih dan arus globalisasi yang semakin hebat sehingga banyak persaingan dalam berbagai hal yang menuntut peningkatan kualitas Sumber Daya Manusia (SDM) terutama untuk menciptakan SDM yang berkualitas dan berprestasi (Erfandi, 2008).

Metode untuk meningkatan SDM diantaranya adalah melalui pendidikan, karena pendidikan dapat diartikan sebagai sebuah proses dengan metode-metode tertentu sehingga orang memperoleh pengetahuan, pemahaman, dan cara bertingkah laku sesuai dengan kebutuhan. Proses belajar mengajar dilakukan dan diusahakan secara sengaja untuk mengembangkan pengetahuan siswa agar tumbuh dan berkembang sesuai dengan tujuan yang diharapkan. Proses belajar mengajar juga tidak akan ada manfaatnya apabila siswa tidak memiliki motivasi terhadap pembelajaran tersebut. Motivasi belajar sangat erat sekali hubungannya dengan perilaku siswa disekolah. Motivasi belajar dapat membangkitkan dan mengarahkan peserta didik untuk mempelajari sesuatu yang baru. Bila pendidik atau guru bisa membangkitkan motivasi belajar anak didik, maka mereka akan memperkuat respon yang telah dipelajari (TIM Pengembang Ilmu Pendidikan FIP-UPI,2007).

Menurut Purwanto (2007), bahwa setiap motivasi itu berpengaruh kuat terhadap dengan tujuan dan juga cita-cita. Semakin berharga suatu tujuan maka semakin kuat pula motivasi. Motivasi itu sangat berguna bagi tindakan atau perbuatan seseorang.Iskandar (2009), mengemukakan bahwa motivasi ini tumbuh karena ada keinginan untuk mengetahui dan memahami sesuatu dan mendorong serta mengarahkan minat belajar siswa sehingga sungguh-sungguh untuk belajar dan termotivasi untuk mencapai prestasi.

Kenyataan yang ada, banyak siswa yang motivasi belajarnya kurang bahkan ada siswa yang tidak memiliki motivasi dan semangat untuk belajar. Seiring dengan kemajuan zaman, siswa dihadapkan pada tuntutan situasi yang begitu kompleks sebagai suatu hal yang sulit untuk dipenuhi. Hal ini dapat disebabkan karena karakteristik pada masing-masing siswa berbeda. Salah satu contohnya siswa yang mengalami kesulitan dalam hal belajarnya dikarenakan pada zaman yang semakin berkembang seperti sekarang banyak hal yang membuat siswa malas belajar, hal ini disebabkan pelajar lebih terfokus dengan Gadget atau Smartphone. Di sekolah menengah atas yang rata-rata siswa nya mempunyai Smartphone yang mendukung kebutuhan para siswa untuk berkomunikasi melalui media sosial yang saat ini sedang berkembang pesat pada setiap orang yang memiliki Smartphone (Lestari, 2010).

Penggunaan internet khusunya penggunaan media sosial dengan waktu yang lama tidak hanya dapat mengganggu konsentrasi belajar bagi remaja, tetapi juga memberikan dampak negatif lainnya seperti mengalami gangguan pola tidur yang menyebabkan daya konsentrasi menjadi menurun, dan merusak indera penglihatan karena seringnya terpapar sinar radiasi dari smartphone (Ibrahim, 2011). 


\section{METODE}

Jenis penelitian yang digunakan dalam penelitian ini adalah Deskriptif Korelasi. Desain penelitian ini menggunakan pendekatan Cross Sectional. Populasi yang dilakukan dalam penelitian ini adalah remaja di SMAN 01 Gringsing yang berjumlah 593 siswa. Untuk menentukan jumlah sampel, maka digunakan rumus Slovin. Teknik pengambilan sampel yang dilakukan dengan menggunakan teknikSimple Random Sampling. Uji statistik yang digunakan adalah Chi-Square.

\section{HASIL}

Responden pada penelitian ini berjumlah 239 siswa-siswa SMAN 1 Gringsing, di Desa Karanganyar Kecamatan Gringsing Kabupaten Batang, dengan gambaran sebagai berikut :

Tabel 1.

Distribusi frekuensi responden berdasarkan usia $(n=239)$.

\begin{tabular}{ccccccc}
\hline Variabel & Mean & Med & Min & Max & St.Dev & $95 \%$ CI \\
\hline Usia & 15,97 & 16,00 & 15 & 17 & 0,801 & $15,87-16,07$ \\
\hline
\end{tabular}

Tabel 1 menunjukkan bahwa pengguna media sosial rata-rata adalah responden berusia 15,97, median 16,00 usia minimumnya adalah 15 tahun, pengguna media sosial usia maksimum 17 tahun dan standar deviasi. Untuk estimasi interval 95\% rata-rata umur responden berada pada selang 15,87 s/d 16,07.

Tabel 2.

Distribusi Frekuensi Berdasarkan Jenis Kelamin, Durasi Penggunaan Media Sosial, dan Motivasi Belajar (n= 239).

\begin{tabular}{|c|c|c|}
\hline Variabel & Frekuensi & Persentase $(\%)$ \\
\hline \multicolumn{3}{|l|}{ Jenis Kelamin } \\
\hline Laki-laki & 113 & 47,3 \\
\hline Perempuan & 126 & 52,7 \\
\hline \multicolumn{3}{|c|}{ Durasi Penggunaan Media Sosial } \\
\hline Rendah & 152 & 63,6 \\
\hline Sedang & 55 & 23,0 \\
\hline Tinggi & 32 & 13,4 \\
\hline \multicolumn{3}{|l|}{ Motivasi Belajar Siswa } \\
\hline Rendah & 8 & 3,3 \\
\hline Sedang & 176 & 73,7 \\
\hline Tinggi & 55 & 23 \\
\hline
\end{tabular}

Tabel 2 menunjukkan bahwa jumlah terbanyak pengguna media sosial berdasarkan jenis kelamin adalah perempuan $126(52,7 \%)$ responden sedangkan laki-laki 113 (47,3\%) responden. Berdasarkan variabel durasi penggunaan media sosialnya didapatkan hasil terbanyak masuk dalam kategori rendah yaitu 152 responden $(63,6 \%)$, kategori sedang berjumlah 55 responden $(23,0 \%)$, dan kategori tinggi yaitu 32 responden $(13,4 \%)$. Dan berdasarkan varibel motivasi belajar didapatkan hasil terbanyak yaitu siswa masuk dalam kategori motivasi belajar sedang yaitu 176 responden $(73,6 \%)$, kategori motivasi belajar rendah yaitu 8 responden $(3,3 \%)$, dan dalam kategori motivasi belajar tinggi sebanyak 55 responden $(23 \%)$.

Tabel 3.

Tabulasi silang antara durasi penggunaan media sosial dengan motivasi belajar remaja $(n=239)$

\begin{tabular}{|c|c|c|c|c|c|c|c|c|c|}
\hline \multirow{3}{*}{$\begin{array}{c}\text { Durasi } \\
\text { penggunaan } \\
\text { medsos }\end{array}$} & \multicolumn{6}{|c|}{ Motivasi belajar siswa } & \multirow{2}{*}{\multicolumn{2}{|c|}{ Total }} & \multirow{3}{*}{$\rho$ Value } \\
\hline & \multicolumn{2}{|c|}{ Rendah } & \multicolumn{2}{|c|}{ Sedang } & \multicolumn{2}{|c|}{ Tinggi } & & & \\
\hline & $\mathrm{f}$ & $\%$ & $f$ & $\%$ & $\mathrm{f}$ & $\%$ & $\mathrm{f}$ & $\%$ & \\
\hline Rendah & 0 & 0 & 99 & 41,4 & 53 & 22,2 & 152 & 63,6 & \multirow{3}{*}{0,000} \\
\hline Sedang & 0 & 0 & 53 & 22,4 & 2 & 8 & 55 & 23,0 & \\
\hline Tinggi & 8 & 3.3 & 24 & 100 & 0 & 0 & 32 & 13.4 & \\
\hline
\end{tabular}

\section{PEMBAHASAN}

\section{Karakteristik Responden}

1. Usia

Hasil penelitian menunjukkan bahwa rata-rata usia responden adalah 16 tahun. Sekitar $80 \%$ remaja di Indonesia menggunakan media sosial berada pada usia 12 sampai 19 tahun, penggunaan media sosial dan digital sudah menjadi bagian dalam kehidupan sehari-hari anak muda di Indonesia. Di Amerika menyatakan bahwa 94\% remaja Amerika melakukan aktivitas online di media sosial untuk mencari sumber atau bahan 
dalam menyelesaikan tugas sekolah (Qomariyah, 2009).

\section{Jenis Kelamin}

Hasil penelitian menunjukkan bahwa jenis kelamin sangat mempengaruhi perilaku manusia, hal ini juga berlaku pada penggunaan media sosial. Pengguna media sosial dengan jumlah terbanyak adalah perempuan dengan jumlah responden $34(54,8 \%)$, dan terendah adalah lakilaki yaitu $28(45,2 \%)$ responden pengguna media sosial. Laki-laki justru cenderung menggunakan media sosial hanya untuk kepentingan berbisnis dan urusan pribadinya, sedangkan sebagai manusia yang pandai bersosialisasi perempuan berada diposisi lebih unggul dibandingkan dengan laki-laki dalam menggunakan media sosial untuk urusan menjalin relasi, menunjang penampilan, urusan pribadi maupun urusan bisnis (McCune, 2011).

\section{Motivasi Belajar}

Motivasi sangatlah penting bagi remaja yang duduk dibangku sekolah, karena dengan motivasi siswa dapat menyadari betapa pentingnya belajar untuk masa depan. Hasil penelitian yang didapatkan bahwa motivasi belajar siswa-siswi nya mempunyai tingkat motivasi belajar yang masuk dalam kategori motivasi sedang yaitu 176 $(73,6 \%)$ siswa dari 239 responden. Motivasi sangat berpengaruh terhadap pencapaian cita-cita siswa, dengan adanya motivasi siswa lebih terdorong untuk berproses menggapai cita-cita mereka. Motivasi sangat diperlukan dalam proses belajar, sebab tanpa adanya motivasi dalam belajar, maka tidak akan mungkin melakukan aktifitas belajar (Djamarah, 2007).

\section{Durasi Penggunaan Media Sosial}

Media sosial memang sangatlah penting bagi kehidupan manusia apalagi diera sekarang, manusia cenderung memerlukan informasi yang tepat dan akurat untuk memenuhi kebutuhannya. Dengan menggunakan media sosial yang semakin lama semakin bisa menjadikan kepuasan tersendiri untuk setiap penggunanya, kadang mereka melupakan satu hal yaitu lama waktu atau durasi yang mereka pergunakan untuk mengakses media sosial tersebut (Dosi, 2013).

Hasil penelitian yang didapatkan siswa yang menggunakan durasi media sosial dengan jumlah terbanyak masuk dalam kategori sedang yaitu 3-4 jam berjumlah $31(50 \%)$ siswa, sedangkan menggunakan durasi media sosial dengan jumlah terendah masuk dalam kategori lama yaitu 5-6 jam dengan jumlah 19 siswa $(30,6 \%)$, sedangkan sisanya masuk dalam pengkategorian siswa dengan durasi penggunaan media sosial singkat yaitu 1-2 jam yang berjumlah $12(19,4 \%)$ siswa.

Kegiatan mengakses jerjaring sosial sudah menjadi rutinitas dikalangan remaja. Pada dasarnya kegiatan ini merupakan salah satu kemajuan pada bidang teknologi informasi dan komunikasi yang sudah merambah diberbagai bidang kehidupan salah satunya dibidang pendidikan dan pengajaran yang digunakan untuk mempermudah dalam pertukaran informasi yang terkait pada ruang dan waktu. Kehadiran situs jejaring sosial tentu membawa dampak negatif dan positif terhadap dunia pendidikan, khususnya pada motivasi belajar siswa (Afrianingrum dan Mulyono, 2012).

\section{SIMPULAN DAN SARAN \\ Simpulan}

1. Karakteristik responden pada usia rata-rata penggunanya adalah remaja berusia 16 tahun. Jenis kelamin penggunaan media sosial tertinggi adalah perempuan.

2. Mayoritas responden di SMAN 1 Gringsing Kecamatan Gringsing Kabupaten Batang menggunakan media sosial dengan durasi rendah.

3. Mayoritas remaja di SMAN 1 Gringsing Kecamatan Gringsing Kabupaten Batang yang memiliki motivasi belajar dengan skor tertinggi masuk dalam kategori sedang .

\section{Saran}

\section{Bagi Remaja SMA}

Remaja sebaiknya mampu menyesuaikan waktu penggunaan media sosial dengan baik sehingga tidak lalai terhadap tugasnya sebagai pelajar. Siswa juga diharapkan menggunakan media sosial dengan baik dan bijak sesuai dengan kebutuhan untuk penambah informasi serta wawasan.

\section{Bagi Masyarakat}

Dalam mencari informasi atau untuk penambah wawasan, media sosial adalah solusi yang paling tepat untuk memenuhi kebutuhan pribadi maupun sosial bagi masyarakat yang menggunakannya. Tetapi akan lebih baik jika diperhatikan juga durasi atau waktu yang normal serta keadaan yang memungkin untuk mengakses media sosial, karena jika digunakan dalam waktu dan keadaan yang salah media sosial dapat mengakibatkan dampak buruk terhadap penggunanya. 
3. Bagi Institusi Pendidikan

Bagi institusi pendidikan sebaiknya lebih meningkatkan fasilitas untuk mengakses internet, agar proses belajar mengejar pada saat perkuliahan tidak terganggu dalam mecari informasi atau referensi. Bagi mahasiswa sebaiknya juga menunjang wawasan mereka dari buku-buku yang ada, hindari pembuatan tugas kuliah atau yang lainnya dengan cara mengcopy-paste materi dari blog yang ada karena itu sama saja tidak mencari referensi dengan benar justru meningkatkan sifat malas dan tidak berkembang pada mahasiswa.

4. Bagi Peneliti Selanjutnya

Diharapkan mampu menambahkan kalimat yang pas untuk instrumen dalam kuesioner durasi penggunaan media sosial sehingga didapatkan hasil yang lebih jelas. Menambahkan teori pendukung dan penelitian lebih lanjut dengan menggunakan responden yang lebih besar dan representatif dengan metode yang akurat serta meneliti faktor lain selain durasi penggunaan media sosial dan motivasi belajar remaja SMA. Menambahkan teori tentang bagaimana penggunaan durasi dalam media sosial secara 24 jam baik disekolah maupun dirumah. Mampu menganalisa penggunaan media sosial di smartphone atau di PC.

\section{DAFTAR PUSTAKA}

Asdani Kindarto. (2010). Efektif Blogging dengan Aplikasi Facebook. Jakarta : Elex Media Komputindo

Dahlan, Sopiyudin. (2011). Statistik untuk Kedokteran dan Kesehatan. Edisi 5. Jakarta : Salemba Merdeka.

Djamarah, Syaiful Bhari. (2007). Psikologi Pendidikan. Jakarta : Rineka Cipta.

Dosi. ((2013). Motif Penggunaan dan Interaksi Sosial di Twitter.

Gatot. S. (2014). Siaran Pers Tentang Riset Kominfo dan Unicef Mengenai Perilaku Anak dan Remaja dalam Menggunakan Internet. Pusat Data dan Saarana Informatika Kementrian Komunikasi dan Informatika.

Hanjani, Febyuka. (2013). Peningkatan Kebutuhan akan Media Sosial pad Remaja. Personal Growth, Conseling and Development Center.
Hutahahean, N. Br. (2012). Hubungan Penggunaan Situs Jejaring Sosial Terhadap Hasil Belajar Fisika Siswa Kelas XII IPA SMA Di Kota Medan Tahun Ajaran 2012/2013. Skripsi. Universitas Negeri Medan.

Ibrahim, Idi Subandi. (2011). Kritik Budaya Komunikasi, Yogyakarta. Jalasutra.

Iskandar. (2009). Psikologi Pendidikan Sebuah Orientasi Baru.Ciputat: Gaung.

Mazman, S. G \& Usluel, Y. K. (2011). Gender Differences in Using Social Network. TOJET: The Turkish Online Jurnal Of Education Technology. 